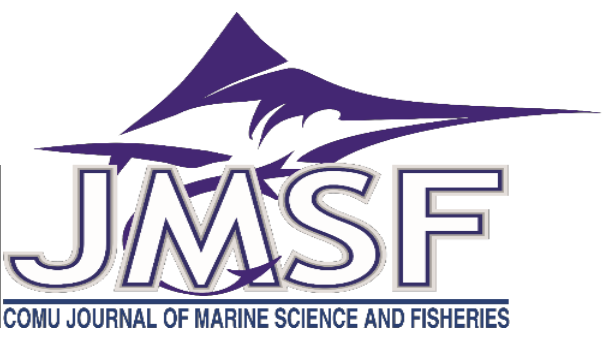

REVIEW

\title{
Preparedness of European Countries in Terms of Marine Pollution by Hazardous and Noxious Substances
}

\author{
Erdem Kan ${ }^{1}$, Özgür Tezcan ${ }^{2} *$ \\ ${ }^{1}$ Dokuz Eylül Üniversitesi, Denizcilik Fakültesi, Deniz Ulaștırma İșletme Mühendisliği Bölümü / İzmir \\ ${ }^{2}$ Çanakkale 18 Mart Üniversitesi, Gelibolu Piri Reis Meslek Yüksekokulu, Ulaştırma Hizmetleri Bölümü / Çanakkale \\ Correspondent: ozgurtezcan@comu.edu.tr \\ Received: 11.12.2019 Accepted: 11.03.2020 \\ Erdem KAN: Orcid 0000-0001-5888-3211, Özgür TEZCAN: Orcid 0000-0003-3004-7443
}

How to cite this article: Kan, E., \& Tezcan, Ö., (2020). Preparedness of European countries in terms of marine pollution by hazardous and noxious substances. COMU J. Mar. Sci. Fish, 3(1): 57-65. DOI: 10.46384/jmsf.658113

\begin{abstract}
Various pollutants cause marine pollution which produces multi-layered problems. Besides other hazardous substances, pollution from hazardous and noxious substances (HNS) threat marine ecosystems seriously. Therefore, prevention and emergency response to this kind of pollution become important. The aim of this study is to determine the preparedness and capability of European countries in case of marine pollution caused by HNS. In this context, emergency response plans of the countries were investigated, the data presented via tables and a comparative view was provided.
\end{abstract}

Keywords: Hazardous and Noxious Substances (HNS), Marine Pollution, European Waters, HNS Spill Preparedness, Pollution Management

\section{Avrupa Ülkelerinin Tehlikeli ve Zararlı Kimyasal Maddelerden Kaynaklı Deniz Kirliliğine Hazırlıkı Olma Durumları}

Özet: Deniz kaynaklarının çeşitli kirletici maddelerle kirletilmesi çok katmanlı sorunlar ortaya çıkarmaktadır. Diğer zararlı maddelerin yanı sıra, tehlikeli ve zararlı kimyasal maddelerden (TZKM) kaynaklanan kirlilikler deniz ekosistemlerini ciddi biçimde tehdit etmektedir. Bu nedenle, bu tür kirliliklerin önlenmesi ve acil müdahale yöntemleri önem arz etmektedir. Bu çalışmanın amacı, Avrupa ülkelerinin TZKM kaynaklı deniz kirliliği durumlarında mevcut acil müdahale konusundaki yeterliliklerinin belirlenmesidir. Bu kapsamda, ülkelerin acil müdahale planları ile ilgili doküman incelemesi yapılmıştır. Ülkelerin TZKM kirlilikleri ile mücadele durumları ile ilgili elde edilen veriler tablolaştırılmış ve karşılaştırmalı bir bakış sağlanmıştır.

Anahtar Kelimeler: Tehlikeli ve Zararlı Kimyasal Madde (TZKM), Deniz Kirliliği, Avrupa Denizleri, HNS Kirliliğine Hazır Olma, Kirlilik Yönetimi

\section{Giriş}

Dünya genelinde tehlikeli ve zararlı kimyasal madde (TZKM) taşımacıllı̆ının büyük bir çoğunluğu gemiler ile gerçekleştirilmektedir. Her geçen gün TZKM'ye olan ihtiyaç artmakta ve bu nedenle bu maddelerin üretimi hızla çoğalmaktadır. Artan talep, deniz taşımacılığında TZKM'nin payına da yansımaktadır. $\mathrm{Bu}$ büyümeyle birlikte denizlerde TZKM dökülmesi nedeniyle olan kirliliğe müdahale gereksinimi gün geçtikçe daha önemli hale gelmektedir (Neuparth ve ark., 2011).
Dünya denizlerinde yaşanan TZKM sızıntısı veya döküntüsü sebebiyle yaşanan kirlilikler ekosistemin olumsuz biçimde etkilenmesine neden olmaktadır (Cunha ve ark., 2015). Bu etkiye maruz kalan bir ekosistem hem ekonomik boyutta ülkelere hem de çevresel boyutta canlılara olumsuz etkiler yansitmakta ve ülkelerin besin, turizm ve ticaret gibi kaynaklarında zarara neden olmaktadır. Denizde meydana gelen petrol dökülmelerine oranla kimyasal dökülmeler daha az sıklıkla meydana gelmektedir. Kimyasal maddelerin taşınma miktarı petrol ürünlerine kıyasla daha az olsa da ortaya çıkacak 
potansiyel risk daha fazla olabilir (Sormunen ve ark., 2015). Kimyasal maddeler petrol ürünlerine göre çok daha zehirli olabilmekte ve değişik kimyasal maddelerle karışmaları halinde oldukça tehlikeli sonuçlar doğurabilecek karışımlar ortaya çıkabilmektedir (Hänninen ve Rytkönen, 2006). TZKM'den kaynaklanabilecek kirlilikler, çevresel koşullardan etkilenerek hem biyolojik çevre hem de insan sağlığı için ciddi tehdit oluşturmaktadır. Bu etkilerin en aza indirgenmesi için, Uluslararası Denizcilik Örgütü (International Maritime Organization-IMO) tarafindan hazırlık ve müdahaleye yönelik gerekli protokolleri içerisinde barındıran "Tehlikeli ve Zararlı Maddelerin Kirlilik Olaylarına Hazırlık, Müdahale ve İş birliği Protokolü" (Protocol on Preparedness, Response and Co-operation to Pollution Incidents by Hazardous and Noxious Substances / OPRC-HNS)" 2000 y1lında oluşturulmuştur (IMO, 2019).

Petrol kirliliği nedeniyle olan sızıntı ve kirliliğin çevresel etkileri önceden yaşanan ciddi kazalarla deneyimlenmiş olsa da TZKM kirlilikleri ve sızıntıları konusunda çevresel etki ve müdahale yöntemleri bakımından rol alınabilecek çapta olaylar neyse ki yaşanmamıştır. Bununla birlikte, bu tür kazaların etkileri ve ekosisteme vereceği zararın boyutları ile ilgili kesin bulgular elde edilememiştir. Petrol kirliliklerinden farklı olarak, bu tür maddelerin farklı fiziksel durumlar gösteriyor olması (buharlaşma, çözünme, batma ve yüzme vb.) etki boyutunun tahminini ve acil müdahale işlemlerini zorlaştırmaktadır (Neuparth ve ark., 2013).

TZKM'nin bu olumsuz özellikleri nedeniyle, oluşacak deniz sızıntısı ve kirliliğine karşı ülkelerin hazırlıklı olması gerekmektedir. Bu nedenle OPRCHNS kapsamında acil müdahale ekipleri kurulmalı, bu ekiplerin kapasitelerinin ve ekipmanlarının yeterli hale getirilmesi sağlanmalı, akademik ve bilimsel destek amaçlı birimler kurulmalı ve sürekli eğitim ile talimler yapılmalidir.

$\mathrm{Bu}$ araştırma, TZKM'ye dayalı herhangi bir deniz kirliliği durumu yaşandığında Avrupa'da denize kıyısı bulunan ülkelerin acil müdahale kapasitesinin ve yeterliliklerinin tespit edilip karşılaştırılmasını amaçlamaktadır. Bu amaç çerçevesinde, bu ülkelerin OPRC-HNS 2000 protokolü kapsamında karşılaştırılması ve incelenmesi amacıyla Avrupa Denizcilik ve Emniyet Ajansı'nın (ADEA) 2013 yılında hazırladığ 1 "Avrupa Birliği Üye Ülkelerinin Tehlikeli ve Zararlı Kimyasal Maddelerden Kaynaklanan Deniz Kirlilikleri ile ilgili Politika ve Operasyonel Müdahale Kapasiteleri” raporundaki başlıklar esas alınmıştır. Raporda yer alan ülkelerin TZKM ile ilgili hazırlıklı olma durumları incelenmiş, bu ülkeler ile ilgili bilgiler Uluslararası Tanker Sahipleri Kirlilik Federasyonu'nun (UTSKF) ülkelerin kirlilik durumlarına müdahale olanaklarına yönelik değerlendirmeleri ile desteklenmiştir. Bu çerçevede Avrupa'da denize kıyısı bulunan 24 ülkenin TZKM hazırlık durumları aşağıdaki biçimde derlenmiştir.

\section{AB Ülkelerinin TZKM için Hazır Olma Durumları}

Belçika, OPRC-HNS 2000 protokolüne taraftır. Ancak, bu protokolün tüm hükümleri, mevcut ulusal mevzuat ve bölgesel anlaşma hükümleri kapsamında bulunmaktadır. Risk analizinin güncellenmesi 2008 yılında gerçekleştirilmiştir. Belçika'nın ulusal müdahale stoklarını geliştirmesi ve ilave ekipman ile tamamlama ihtiyacı ortaya çıkmıştır. Buna ek olarak günümüzde bu eksiklikler kısmen kapatılmıştır. Deniz çevresindeki kirlilik durumları ile ilgili olarak gözlemlenmesi, izlenmesi ve değerlendirilmesi amacıyla birçok özel cihazların temini Belçika tarafından karşılanmıştır. Belçika'nın deniz kirliliği olaylarına tepki verebilme kabiliyeti sınırlıdır. Belçika'nın TZKM nedeniyle oluşacak bir sızıntı ile ilgili deniz olaylarıyla uğraşacak özel bir gemisi bulunmamaktadır. Bu konuda Belçika Deniz Kuvvetleri mayın gemileri ve sonar ekipmanlar ile hizmet vermektedir. Kirlilik kazalarına müdahale etmek için denizcilikle ilgili çok özel bir eğitime ihtiyaç duyulmaktadır. (OECD, 2007a; EMSA, 2013).

Bulgaristan, OPRC-HNS 2000 protokolüne taraf olmamıştır. Bu nedenle gerekleri yerine getirmek için kendi ulusal mevzuatları bulunmaktadır. Herhangi bir kirlilik halinde renkli yüzer maddelerin ve paketli malzemelerin izlenebilmesine imkân veren gemilere sahiptir. Bulgaristan'ın kirlilik yaratan deniz olaylarına müdahale kabiliyeti çok sınırlıdır. Oluşan sızıntıları önlemek ve TZKM nedeniyle oluşan kirliliğe müdahale için herhangi bir depolama sistemi bulunmamaktadır. TZKM olaylarına müdahale edecek herhangi bir ekibi de bulunmamakta ve böyle bir ekibin yetiştirilmesi için kullanılabilecek bir eğitim programı da yoktur (EMSA, 2013; Oral, 2013).

Kıbrıs, OPRC-HNS 2000 protokolüne taraf olmamıştır ve ulusal bir acil durum prosedürü bulunmamaktadır. Ayrıca, deniz taşımacılığı ile ilgili oluşan TZKM nedeniyle oluşan kirliliğe ilişkin bir risk değerlendirmesine sahip değildir. Denizde oluşan döküntülerin izlenmesi için herhangi bir özel ekipmana sahip olmayan Kıbrıs'ın bu tarz kirlilik olaylarına tepki verme kabiliyeti de çok kısıtlıdır. TZKM nedeniyle oluşan kirliliğe neden olan kazalardan kaynaklanan deniz kirliliğine müdahale etmek için herhangi bir deniz aracı bulunmayan Kıbrıs'ta liman alanları da dâhil karadaki olaylara itfaiye müdahale etmektedir. (EMSA, 2013).

Danimarka, OPRC-HNS 2000 protokolüne taraftır. Ulusal acil durum planlarında TZKM nedeniyle oluşan kirlilik durumlarıyla mücadele ilgili olarak herhangi bir plan bulunmamaktadır fakat TZKM taşımacılığ yapılmıştır (Danish Maritime Authority, 2009). Bu 
sızıntıların izlenmesi için bir görüntüleme ekipmanı ve alınan numunelerin ölçüldüğü cihazlara sahiptir. Buna ilave olarak havadan gözlem yapabilme imkânı da bulunmaktadır. Danimarka'nın TZKM nedeniyle oluşan sızıntıları içeren deniz olaylarına müdahale kabiliyeti çok sınırlıdır ve çoğunlukla petrol kirliliği müdahalesi ile aynı kaynaklara dayanmaktadır. TZKM içeren deniz olayları ile ilgili olarak uzman bir müdahale ekibi bulunmamaktadır (OECD, 2007b; EMSA, 2013).

Estonya, OPRC-HNS 2000 protokolünü onaylamıştır. Ulusal acil durum planlarında TZKM sonucu oluşan sızıntılarla ilgili durumlarda mücadele ilgili olarak herhangi bir planı bulunmamaktadır. Ulusal risk değerlendirmeleri kapsamında deniz taşımacılığ 1 başlığı altında her yıl bu gibi durumlar göz önüne alınmakta ve deniz sızıntılarına karşı duyarlı ekolojik ve sosyo-ekonomik alanlar belirlenmektedir. TZKM döküntülerinin izlemesi için bazı özel ekipmanlara sahip olan Estonya, gözlem uçağı, hava radarı ve kızıötesi tarama cihazlarına sahiptir. TZKM için diğer ülkelerde olduğu gibi petrol kirliliğinde kullandıkları ekipmanları kullanmaktadır. Ayrıca, Estonya'da TZKM kirliliğine karşı müdahale için ayrı bir ekip bulunmamaktadır (ITOPF, 2018a).

Finlandiya, OPRC-HNS 2000 protokolünü onaylamıştır. Finlandiya mevzuatı TZKM ve petrol ürünleri kökenli deniz kirliliği durumunda farklı otoritelerin rollerini ve sorumluluklarını tanımlamaktadır. Ayrıca Finlandiya TZKM nedeniyle yaşanan olası kirliliklerin deniz taşımacılığına etkisini de içeren bir risk değerlendirmesi yapmıştır. Havadan gözlem cihazları ile gemi gözlem cihazları bulunan Finlandiya ayrıca çeşitli numuneleri ölçebilen cihazlar ile deniz üzerindeki durumun izlenmesi için cihazlara sahiptir. Özel gemileri ve teçhizatları TZKM kirlilik olaylarında kullanmak üzere bünyesinde bulundurmaktadır. Dalgıçlar, Deniz Kuvvetleri, TZKM müdahale uzmanları ve sahil güvenlik güçleri ile bu tarz yaşanan sızıntılara müdahalede bulunmaktadır (ITOPF, 2018b).

Fransa, OPRC-HNS 2000 protokolünü onaylamıştır. Fransa'da TZKM döküntüleri ve petrol kirliliği ile ilgili olarak müdahalede bulunacak uzman ekip ve ekipmanı bulunmaktadır. Ayrıca Akdeniz, Atlantik ve Kuzey Denizi olmak üzere üç adet acil durum planı bulunmakta olup TZKM ve petrol kirliliğinin gözlemlenmesi, değerlendirilmesi ve izlenmesi için birçok özel cihaza sahiptir. $\mathrm{Bu}$ da önceden Fransa'da yaşanan kazalardan ders aldığının bir göstergesidir. Fransa'da donanmanın itfaiye ekipleri tarafından eğitilmiş kirlilik müdahale ekipleri bulunmaktadır (ITOPF, 2018c).

Almanya, OPC-HNS 2000 protokolünü onaylamıştır. Ulusal acil durum planlarında TZKM kirliliği ile yapılacak mücadele planları da mevcut olup gerekli risk değerlendirmeleri de yapılmıştır. Almanya, TZKM ve petrol kirliliği ile mücadele konusunda birçok ekipmana sahiptir. Ayrıca bazı yaşanacak durumlarla ilgili olarak özel eğitimli ekipleri bulunmaktadır (ITOPF, 2018d).

Yunanistan, OPRC-HNS 2000 protokolünü onaylamıştır. Bunun yanında ulusal acil durum planında TZKM ve petrol kirliliği durumlarına ait süreçler bulunmaktadır. Ancak, yapılan herhangi bir risk değerlendirmesi bulunmamaktadır. TZKM kirliğini ilgilendiren deniz kazalarına müdahale etme kapasitesi Yunanistan'ın çok sınırlıdır. Devlet elinde temizleme çalışmaları ve müdahale ile ilgili çok fazla ekipman bulunmamaktadır. Bununla birlikte kirliliğe müdahale için herhangi bir ekip de bulunmamaktadır (OECD, 2009).

İzlanda, OPRC-HNS 2000 protokolünü onaylamamıştır. Bununla birlikte, ulusal acil durum planında TZKM ve petrol kirliliği durumlarına ait planlar ve yapılan herhangi bir risk değerlendirmesi de bulunmamaktadır. İzlanda'nın TZKM sızıntılarına neden olan deniz kazalarına müdahale etme kapasitesi çok sınırlıdır. Temizleme çalışmaları ve müdahale ile ilgili ekipmanları kısıtlıdır. Ayrıca, kirliliğe müdahale için herhangi bir ekibi de bulunmamaktadır (ITOPF, 2018e).

İrlanda, OPRC-HNS 2000 protokolünü uygulamak için ulusal mevzuat çıkarmıştır fakat anlaşmaya uluslararası boyutta taraf değildir. Ulusal acil durum eylem planlarında ise TZKM ve deniz kirliliklerine yönelik acil durum planları belirlenmiş ve risk değerlendirmesi için gerekli uygulamalar tamamlanmıştır. TZKM ve petrol kirliliği sonucu oluşan sızıntıları izlemek amacıyla bir sistemi bulunmasa da bir simülasyon ile modelleme imkânına sahiptir. İrlanda'nın hali hazırda oluşacak bir kirliliğe müdahale etme imkânı sınırlıdır. Bununla ilgili denizde müdahale edecek bir deniz ekibi bulunmamaktadir (OECD, 2010).

Türkiye, OPRC-HNS 2000 protokolüne 2003 yılında taraf olmuş ve ulusal mevzuatında Deniz Çevresinin Petrol ve Diğer Zararlı Maddelerle Kirlenmesinde Acil Durumlarda Müdahale ve Zararların Tazmini Esaslarına Dair Kanunu 2005 yllında yürürlüğe sokmuştur (Çiçek, 2018). Türkiye'de kirlilik olaylarına müdahale amacıyla oluşturulmuş bir adet "Ulusal Deniz Emniyeti ve Acil Müdahale Merkezi” (Tekirdağ), bir adet "Bölgesel Acil Müdahale Merkezi” (Antalya) ve kıyı şeridine belirli aralıklarla yerleştirilmiş 19 adet "Acil müdahale istasyonu" kurulmasına ilişkin çalışmalar sürdürülmektedir (KEGM, 2019). TZKM kapsamında oluşacak kirlilikleri izleme ekipmanları olmasına karşın bu ekipmanların geliştirilmeye ihtiyacı bulunmaktadır. T.C. Ulaştırma ve Altyapı Bakanlığı acil müdahale merkezlerinin kurulması, tatbikat ve eğitimlerin yönetimi gibi konularda projeler hazırlayarak uygulamaya geçirilmesi 
amacıyla ulusal ve uluslararası kurum ve kuruluşlarla anlaşmalar yapmıştır. (Çiçek, 2018).

Letonya, OPRC-HNS 2000 protokolüne onay için hazır olsa da finansal kisitlamalar nedeniyle onaylama ertelemiştir. Ancak, Ulusal Petrol Sızıntısı Acil Eylem Planı OPRC- TZKM protokolü çerçevesinde 2010 yılında yenilenmiştir. Kirlilikle ilgili risk analizi 2014 yılında yapılmıştır. Letonya, TZKM kirliliği kapsamında bütün izleme sistemlerine sahiptir ancak oluşacak bir döküntü ve kirlilik olayına müdahale amacıyla kullanılan özel gemileri ve müdahale ekipleri olmadığından dolayı müdahale kapasitesi oldukça sınırlı kabul edilmektedir. Ülkenin bu tarz kirliliklere müdahale ile ilgili gemilere, hava araçlarına ve personeline yönelik herhangi bir eğitim programı da bulunmamaktadır. Diğer üye ülkelerdeki bir kirlilik durumunda Letonya, ordu kaynakları ile bilim ve sanayi topluluklarından uzman yardımı sunabilmektedir (ITOPF, 2018f).

Litvanya, OPRC-HNS 2000 protokolü henüz onaylanmamış olup onay tarihi ile ilgili bir belirsizlik vardır. Bununla birlikte Litvanya Hükümeti protokol ile ilgili gerekli hazırlıkları sürdürmektedir. Ulusal acil eylem planı TZKM protokolünü kapsayacak hükümler taşımamakta olup konu ile ilgili risk analizi yapılmamıştır. TZKM kirliliği izleme kapasitesi ile ilgili özel ekipman ve depolama alanı bulunmayan Litvanya'da kirlilik durumlarında kullanılmak üzere yüzer kreynler ve barçlar geçici olarak kullanıma tahsis edilmek üzere planlanmıştır. TZKM sızıntısı içeren deniz kazaları için özel ekip ve teknik personelin bulunmadığı Litvanya' da bu tip olaylarda Ulusal Çevre Koruma Ajansı Deniz Araştırmaları Departmanı'ndan uzman yardım almayı planlamaktadır. Bu tür sızıntı olayları ile ilgili özel bir eğitim programı bulunmayan Litvanya, diğer üye ülkelerdeki olaylara teknik ve ekipman desteği sağlayamamaktadır. (EMSA, 2013).

Malta OPRC-HNS 2000 protokolünü onaylamıştır. 2009 yılında yenilenen Ulusal Acil Durum Planı TZKM kirliliklerine müdahale yöntemlerini kapsamaktadır. Konu ile ilgili risk analizi Ulusal Acil Eylem Planı hazırlanmadan önce yapılmıştır. Kirlilik izleme açısından TZKM protokolü kapsamında çoğu ekipmanı bulunduran Malta, özel gemileri olmaması nedeniyle müdahale açısından oldukça kısıtlı olanaklara sahiptir. Malta Sivil Savunma Departmanı TZKM kirliliği müdahale ekipmanı ve personelini bünyesinde barındırmakta ve düzenli eğitimler ile müdahale bilgisini güncellemektedir. Malta diğer üye ülkelerdeki olaylara yardım sağlayamamaktadır. (EMSA, 2013).

Hollanda, arama kurtarma ve acil durum yedekleme hizmetleri ile TZKM kirliliklerine müdahaleyi kapsayan Deniz Acil Durum Müdahale Servisi'ne sahiptir. Ülke OPPRC-HNS 2000 Protokolü'nü onaylamıştır. Ulusal Acil Durum Eylem Planı TZKM kirliliği olaylarını kapsamasa da yeni bir plan hazırlanmaktadır. TZKM olayları ile ilgili risk analizi henüz yapılmamıştır. İzleme açısından yeterli sayılabilecek imkanlara sahip olan Hollanda, müdahale açısından oldukça yetersizdir. Müdahale için özel gemileri olmadığından bu tür müdahalelere uygun özellikli bazı askeri gemiler müdahale için kullanılabilir. Hollanda TZKM olaylarına müdahale ekibine sahiptir. Willem Barentz Denizcilik Koleji yıllık eğitim programları ile TZKM kirliliğine ilişkin müdahalelere katkı sunabilecek kapasitededir. Diğer üye ülkelerde yaşanabilecek bu tarz kirlilik ve sızıntı olaylarına özel ekipmanlar, eğitimli personel, uzman kişiler, hava gözetim olanakları sağlayabilir. (EMSA, 2013).

OPRC-HNS 2000 Protokolünü onaylamış olan Norveç, ulusal acil durum eylem planına TZKM kirlilik olaylarına müdahaleyi eklemiştir. Norveç karasularında bu sızıntılar nedeniyle yaşanacak deniz olaylarına ilişkin risk analizi 2004 yılında yapılmıştır. Deniz kirliliğini izlemek amacıyla bir adet uçak ve çeşitli ekipmanlara sahip olan Norveç'in kirliliğe müdahale ile ilgili olanakları oldukça kısıtlıdır. İki yangın ekibi TZKM kirliliği olaylarına müdahale ile ilgili olarak 2012 yılında oluşturulmuştur ve bu iki ekip düzenli olarak eğitime tabi tutulmaktadır. (EMSA, 2013).

OPRC-HNS 2000 Protokolünü onaylamış olan Polonya, ulusal acil durum eylem planına TZKM kirliliği olaylarına müdahaleyi eklemiştir. Hava, deniz, tahmin yöntemleri gibi izleme olanaklarına sahip olmakla birlikte geniş müdahale imkânı bulunmaktadır. Bununla birlikte ülkede ordu kuvvetlerine bağlı donanımlı müdahale ekipleri ile müdahalede kullanılan çok amaçlı bir gemisi bulunmaktadır. Faaliyete geçmesi beklenen Ulusal Tehlikeli Kirlilik Algılama ve Uyarı Sistemi kapsamında eğitim ve talim prosedürleri de bulunmaktadır. (EMSA, 2013; ITOPF, 2018g).

OPRC-HNS 2000 Protokolünü onaylamış olan Portekiz, ulusal acil durum eylem planına TZKM olaylarına müdahaleyi eklemiştir. Ancak TZKM müdahalesi ile ilgili bir risk analizi yapılmamıştır. TZKM kirliliği izleme için özel araçlara sahip olmayan Portekiz aynı zamanda müdahale için çok kısıtlı olanaklara sahiptir. Kirlilik müdahale ekibi olmayan Portekiz'in konu ile ilgili eğitim ve talim prosedürleri de bulunmamaktadır (OECD, 2011; EMSA, 2013).

Romanya, OPRC-HNS 2000 Protokolünü henüz onaylamasa da bunu gerçekleştirmek için ciddi adımlar atılmaktadır. Ulusal Acil Durum Eylem Planı TZKM kirliliklerini içermektedir ve bununla ilgili risk analizinin yapılması amaçlanmıştır. Romanya, kirlilik izleme faaliyetlerini teknik personel ve ekipmana sahip bazı firmalar ile yürütmektedir. Kirliliğe müdahale ise çok kısıtlı olup petrol kirliliklerine müdahale ekipmanları ile sınırlıdır. Romanya'nın Ulusal Acil Durum Eylem Planı 
çerçevesinde eğitim ve talim prosedürleri bulunmaktadır. (ITOPF, 2019h).

Slovenya, OPRC-HNS 2000 protokolünü onaylamıştır. TZKM kirliliğine ilişkin risk analizini yapmış olan Slovenya, Ulusal Acil Durum Eylem Planına henüz bu tarz yaşanan olaylarla ilgili müdahale süreçlerini dâhil etmemiştir. Slovenya'nın kirlilik izleme ile ilgili özel bir ekipmanı bulunmamakta ve müdahale ile ilgili olanakları oldukça kısıtlıdır. Slovenya'nın TZKM kirliliği ile eğitim ve talim prosedürü bulunmamaktadır (EMSA, 2013; ITOPF, 2018i).

Deniz Arama Kurtarma ve Koordinasyon (MRCC) merkezi olan İspanya, kirlilik izleme ve müdahalesini İspanya Deniz Emniyeti Ajansı (SASEMAR) ile yürütmektedir. OPRC-HNS 2000 protokolünü onaylamış olan İspanya, Ulusal Acil Durum Eylem planında TZKM kirliliği ile mücadeleye yer vermemiş ve bununla ilgili risk analizi yapmamıştır. İspanya'nın kirlilik izleme için özel ekipmanları olmasa da hava ve deniz gözlemi mümkündür. İki adet özel gemiye sahip olan İspanya kirliliğe bu gemiler ile müdahale edebilmektedir. $\mathrm{Bu}$ tür yüklerle ilgili yaşanan olaylar sonucu oluşan kirlilik için özel ekipleri bulunmasa da dört adet çok amaçlı gemi ve yedi adet römorkör kullanılabilir durumdadır. Periyodik olarak eğitim ve talimler yapılmaktadır (EMSA, 2013; ITOPF, 2018j).

OPRC-HNS 2000 Protokolünü onaylamış olan İsveç, ulusal acil durum eylem planına TZKM kirliliği olaylarına müdahaleyi eklemiştir ve bununla ilgili risk analizlerini gerçekleştirmiştir. İsveç bu tarz yaşanan kirlilik olaylarını izleme açısından özel ekipmanlara sahip olmakla birlikte müdahale için eğitimli acil durum müdahale ekibine de sahiptir. İsveç Sahil Güvenlik ekipleri bu tarz madde kirliliklerine müdahale edebilen 70 eğitimli elemana sahiptir. TZKM kirliliği ile mücadele için düzenli olarak eğitim ve talimler yapılmaktadır. (EMSA, 2013; ITOPF, 2018k).

OPRC-HNS 2000 protokolünü onaylamamış olsa da Birleşik Krallık acil durum eylem planına TZKM kirliliğine müdahaleyi eklemiş ve bununla ilgili risk analizini yapmıştır. Kirlilik izleme açısından detaylı ekipmana sahip olan Birleşik Krallık, ticari sözleşmeler ile kirliliğe müdahale olanaklarına da sahiptir. Özel müdahale ekipleri olmasa da çeşitli kuruluşlar aracılığıyla kimyasal madde uzmanları ve kurtarma yardımı sağlayabilmektedir. Ulusal eğitim ve talim prosedürleri olmasa da bazı özel kuruluşlar aracılığı ile bu tarz maddeler ile yaşanan kirlilik olaylarıyla mücadele eğitimleri verilmektedir (EMSA, 2013; ITOPF, 2018m).

Yukarıda incelenen ülkelerin TZKM deniz kirliliği konusundaki durumu ADEA tarafından hazırlanan başliklara göre Tablo 1'de gösterilmiş, ülkelerin konuya yaklaşımlarını karşılaştırma olanağı sunulmuştur. Ek olarak, ülkelerin deniz kirliliği konusunda taraf olduğu uluslararası anlaşmalar da incelenmiş ve ülkelere göre dağılımları Tablo 2'de verilmiştir.

\section{Tartışma}

Avrupa ülkelerinin TZKM kirlilikleri ile ilgili durumlarına ilişkin raporlardan elde edilen veriler Tablo 1 ve Tablo 2'de özetlenmiştir. Buna göre; Finlandiya, Fransa, Almanya, İsveç ve Birleşik Krallık dışındaki ülkelerin TZKM müdahalesi konusunda yeterli olmadıkları anlaşılmaktadır. Kirlilik izleme ilgili çoğu ülkenin altyapısı bulunsa da, Kıbrıs, Yunanistan, İzlanda, Litvanya, Portekiz ve Slovenya'nın izleme donanımına sahip olmadığ görülmektedir. Müdahale, araç ve ekipleri ile bu unsurların eğitimi ile ilgili durum incelendiğinde de ülkelerin oldukça hazırlıksız oldukları görülmektedir. Ulusal mevzuatında bu tür kirlilikler ile ilgili eylem planı bulunan ülke sayısının oldukça az olmasının yanı sıra uluslararası açıdan OPRC-HNS 2000 protokolüne taraf olma konusunda da tam katılım sağlanamamış olması dikkat çekmektedir. Ülkelerin petrol kirliliklerine dayalı konulardaki hassasiyetinin yeterli düzeye ulaştığı görülürken, TZKM kirlilikleri ile henüz bu derecede bir farkındalık olmadığ anlaşılmaktadır. Bu durum, TZKM konusunda henüz çok büyük bir felaket yaşanmamış olması nedeniyle ülkelerin konuya yoğunlaşmaması veya konuyu ötelemesinin bir sonucu olabilir.

$\mathrm{Bu}$ çalışma kapsamında yapılan değerlendirmede, ülkelerin TZKM sızıntısı veya dökülmesi sonucunda oluşacak kirliliklere karşı tam teşekküllü olarak hazır olmadığı sonucuna ulaşılmıştır. Bununla ilgili olarak çoğu Avrupa Birliği ülkesinin gerekli hazırlıkları tamamlamayarak müdahale senaryoları, ekipman ve ekiplerini hazırlamadığı tespit edilmiştir.

TZKM kirliliği yaşandığı durumlar, farklı ve geniş ölçekte sonuçlar doğurabileceğinden (Cunha ve ark., 2015) tüm ülkelerin gerekli önlemleri alarak en kısa zamanda açıklarını kapamaları ve gerekli müdahale hazırlıklarını tamamlamaları gerekmektedir. Unutulmamalıdır ki bu türden yaşanan kirlilikler yalnız insan hayatına değil, ekosisteme de çok büyük zararlar verecektir. Bu tarz yüklerin tehlike ve zararları düşünüldüğünde, ülkeler temelinde önlemler kısmen yeterli olacağından, bir iş birliği halinde tüm ülkelerin konu ile ilgili girişimlerde bulunması önem arz etmektedir. Belirlenen gereklerin yerine getirilmesi için uluslar üstü kurum ve kuruluşlardan fon sağlanmas1, teknoloji paylaşımı yapılması ve süreci kolaylaştırmak adına gerekli olan tüm adımların atılması gerekmektedir. Petrol kirliliklerinin ve bunlara müdahale yöntemlerinin önemi, geçmişte yaşanan katastrofik olaylarla deneyimlenerek anlaşılmıştır. TZKM konusunda bu tür yıkıcı deneyimlerin olmamış olması sevindirici olmakla birlikte, bu tür olaylar yaşanmadan gerekli hassasiyetin sağlanması önem arz etmektedir. 
Tablo 1: Avrupa ülkelerinin OPRC-HNS 2000 kapsamında hazırlıklı olma durumu ve müdahale kapasitelerinin birbiri ile karşılaştırılması

\begin{tabular}{|c|c|c|c|c|c|c|c|c|c|c|c|}
\hline \multirow[b]{2}{*}{ ÜLKE } & \multicolumn{4}{|c|}{ HAZIRLIKLI OLMA } & \multicolumn{7}{|c|}{ MÜDAHALE KAPASITESII } \\
\hline & $\begin{array}{l}\text { OPRC-HNS } \\
\text { Protokolüne } \\
\text { Taraf }\end{array}$ & $\begin{array}{c}\text { Ulusal Acil Durum } \\
\text { Planlan TZKM'yi } \\
\text { Kapsiyor }\end{array}$ & $\begin{array}{c}\text { TZKM ile } \\
\text { ilgili Risk } \\
\text { Planı }\end{array}$ & $\begin{array}{c}\text { TZKM ile } \\
\text { ilgili } \\
\text { Tecrübe }\end{array}$ & $\begin{array}{c}\text { HNS İzleme } \\
\text { Kapasitesi }\end{array}$ & $\begin{array}{l}\text { Müdahale } \\
\text { Kapasitesi }\end{array}$ & $\begin{array}{c}\text { Özel Emniyet } \\
\text { Ekipmanları }\end{array}$ & $\begin{array}{c}\text { Özel } \\
\text { Müdahale } \\
\text { Araçları }\end{array}$ & $\begin{array}{c}\text { Özel } \\
\text { Müdahale } \\
\text { Ekipleri }\end{array}$ & $\begin{array}{c}\text { Bilimsel } \\
\text { Destek }\end{array}$ & $\begin{array}{l}\text { Eğitim ve } \\
\text { Talimler }\end{array}$ \\
\hline Belçika & $\sqrt{ }$ & $\mathrm{X}$ & $\sqrt{ }$ & $\sqrt{ }$ & Sinırlı & Sinırlı & $\sqrt{ }$ & Çok Sinırlı & $\sqrt{1}$ & $\sqrt{ }$ & $\mathrm{X}$ \\
\hline Bulgaristan & $\mathrm{X}$ & $\mathrm{X}$ & $\mathrm{X}$ & $\sqrt{ }$ & Çok Sinırlı & Çok Sınırlı & $\mathrm{X}$ & $\mathrm{X}$ & Çok Sinırlı & $\mathrm{X}$ & $\mathrm{X}$ \\
\hline Kibris & $\mathrm{X}$ & $\mathrm{X}$ & $\mathrm{X}$ & $\mathrm{X}$ & $\mathrm{X}$ & Çok Sınırlı & Sinırlı & $\mathrm{X}$ & $\mathrm{X}$ & $\mathrm{X}$ & $\mathrm{X}$ \\
\hline Danimarka & $\sqrt{ }$ & $\mathrm{X}$ & $\sqrt{ }$ & $\sqrt{ }$ & $\sqrt{ }$ & Sinırlı & $\sqrt{ }$ & $\mathrm{X}$ & Çok Sinırlı & $\sqrt{ }$ & $\sqrt{ }$ \\
\hline Estonya & $\sqrt{ }$ & $\mathrm{X}$ & $\sqrt{ }$ & $\mathrm{X}$ & Çok Sinırlı & Çok Sinırlı & $\mathrm{X}$ & $\mathrm{X}$ & $\mathrm{X}$ & Sinırlı & $\mathrm{X}$ \\
\hline Finlandiya & $\sqrt{ }$ & $\mathrm{X}$ & $\sqrt{ }$ & $\sqrt{ }$ & $\sqrt{ }$ & $\sqrt{ }$ & $\sqrt{ }$ & $\sqrt{ }$ & $\sqrt{ }$ & $\sqrt{ }$ & $\sqrt{ }$ \\
\hline Fransa & $\sqrt{ }$ & $\sqrt{ }$ & $\sqrt{ }$ & $\sqrt{ }$ & $\sqrt{1}$ & $\sqrt{ }$ & $\sqrt{ }$ & $\sqrt{ }$ & $\sqrt{1}$ & $\sqrt{ }$ & $\sqrt{ }$ \\
\hline Almanya & $\sqrt{ }$ & $\sqrt{ }$ & $\sqrt{ }$ & $\sqrt{ }$ & $\sqrt{ }$ & $\sqrt{ }$ & $\sqrt{ }$ & $\sqrt{ }$ & $\sqrt{ }$ & $\sqrt{ }$ & $\sqrt{ }$ \\
\hline Yunanistan & $\sqrt{ }$ & $\sqrt{ }$ & $\mathrm{X}$ & $\sqrt{ }$ & $\mathrm{X}$ & Çok Sinırlı & $\mathrm{X}$ & $\mathrm{X}$ & $\mathrm{X}$ & $\sqrt{ }$ & $\mathrm{X}$ \\
\hline İzlanda & $\mathrm{X}$ & $\mathrm{X}$ & $\mathrm{X}$ & $\mathrm{X}$ & $\mathrm{X}$ & Çok Sinırlı & Sinırlı & $\mathrm{X}$ & $\mathrm{X}$ & Sinırlı & $\mathrm{X}$ \\
\hline İlanda & $\mathrm{X}$ & $\mathrm{X}$ & $\mathrm{X}$ & $\sqrt{ }$ & Sinırlı & Çok Sinırlı & Sinırlı & $\mathrm{X}$ & $\mathrm{X}$ & $\mathrm{X}$ & $\mathrm{X}$ \\
\hline Letonya & $\mathrm{X}$ & $\sqrt{ }$ & $\sqrt{ }$ & $\sqrt{ }$ & Sinırlı & Çok Sinırlı & $\sqrt{ }$ & $\mathrm{X}$ & $\mathrm{X}$ & Sinırlı & $\mathrm{X}$ \\
\hline Litvanya & $\mathrm{X}$ & $\mathrm{X}$ & $\mathrm{X}$ & $\mathrm{X}$ & $\mathrm{X}$ & Çok Sinırlı & $\mathrm{X}$ & $\mathrm{X}$ & $\mathrm{X}$ & Sinırlı & $\mathrm{X}$ \\
\hline Malta & $\sqrt{ }$ & $\sqrt{ }$ & $\sqrt{ }$ & $\sqrt{ }$ & $\sqrt{ }$ & Sinırlı & $\sqrt{ }$ & $\mathrm{X}$ & Sinırlı & Sinırlı & $\sqrt{ }$ \\
\hline Hollanda & $\sqrt{ }$ & $\mathrm{X}$ & $\mathrm{X}$ & $\sqrt{ }$ & $\sqrt{ }$ & Sinırlı & Sinırlı & Çok Sinırlı & $\sqrt{1}$ & $\sqrt{ }$ & $\sqrt{ }$ \\
\hline Norveç & $\sqrt{ }$ & $\sqrt{ }$ & $\sqrt{ }$ & $\mathrm{X}$ & $\sqrt{ }$ & Çok Sinırlı & $\sqrt{ }$ & $\mathrm{X}$ & $\sqrt{ }$ & $\mathrm{X}$ & $\sqrt{ }$ \\
\hline Polonya & $\sqrt{ }$ & $\sqrt{ }$ & $\sqrt{ }$ & $\mathrm{X}$ & $\sqrt{ }$ & Sinırlı & Sinırlı & Sinırlı & Sinırlı & Sinırlı & $\sqrt{ }$ \\
\hline Portekiz & $\sqrt{ }$ & $\sqrt{ }$ & $\mathrm{X}$ & $\sqrt{ }$ & $\mathrm{X}$ & Çok Sinırlı & $\mathrm{X}$ & $\mathrm{X}$ & $\mathrm{X}$ & $\mathrm{X}$ & $\mathrm{X}$ \\
\hline Romanya & $\mathrm{X}$ & $\sqrt{ }$ & $\sqrt{ }$ & $\mathrm{X}$ & $\sqrt{ }$ & Çok Sinırlı & $\mathrm{X}$ & Çok Sinırlı & $\mathrm{X}$ & $\sqrt{ }$ & $\sqrt{ }$ \\
\hline Slovenya & $\sqrt{ }$ & $\mathrm{X}$ & $\sqrt{ }$ & $\mathrm{X}$ & $\mathrm{X}$ & Çok Sinırlı & Sinırlı & $\mathrm{X}$ & Sinırlı & $\sqrt{ }$ & $\mathrm{X}$ \\
\hline İspanya & $\sqrt{ }$ & $\mathrm{X}$ & $\mathrm{X}$ & $\sqrt{ }$ & Sinırlı & Sinırlı & $\mathrm{X}$ & $\sqrt{ }$ & $\mathrm{X}$ & $\sqrt{ }$ & $\sqrt{ }$ \\
\hline İsveç & $\sqrt{ }$ & $\sqrt{ }$ & $\sqrt{ }$ & $\sqrt{ }$ & $\sqrt{ }$ & $\sqrt{ }$ & $\sqrt{ }$ & $\sqrt{ }$ & $\sqrt{ }$ & $\sqrt{ }$ & $\sqrt{ }$ \\
\hline Birleşik Krallık & $\mathrm{X}$ & $\sqrt{ }$ & $\sqrt{ }$ & $\sqrt{ }$ & $\sqrt{ }$ & $\sqrt{ }$ & $\sqrt{ }$ & $\mathrm{X}$ & Sinırlı & $\sqrt{ }$ & Sınırlı \\
\hline
\end{tabular}

Kaynak: EMSA 2013 verilerine taraf devlet listesinin güncellenmesi ile oluşturulmuştur. 
Tablo 2: Çalışma kapsamında incelenen ülkelerin deniz çevresinin korunması ile ilgili taraf oldukları uluslararası anlaşmalar

\begin{tabular}{|c|c|c|c|c|c|c|c|c|c|c|c|c|c|c|}
\hline \multirow[b]{3}{*}{ Ülke } & \multirow{2}{*}{\multicolumn{5}{|c|}{$\begin{array}{c}\text { Önleme ve Emniyet } \\
\text { MARPOL Ekleri }\end{array}$}} & \multicolumn{2}{|c|}{ Kirlilik ile Mücadele } & \multicolumn{7}{|c|}{ Tazminat } \\
\hline & & & & & & \multirow[b]{2}{*}{ OPRC 90} & \multirow[b]{2}{*}{ OPRC-HNS } & \multicolumn{3}{|c|}{ CLC } & \multirow{2}{*}{$\begin{array}{c}\text { Fund } \\
92\end{array}$} & \multirow{2}{*}{$\begin{array}{l}\text { Supp } \\
\text { Fund }\end{array}$} & \multirow[b]{2}{*}{ HNS } & \multirow[b]{2}{*}{ Bunker } \\
\hline & $73 / 78$ & III & IV & $\mathrm{V}$ & VI & & & 69 & 76 & 92 & & & & \\
\hline Belçika & $\sqrt{ }$ & $\sqrt{ }$ & $\sqrt{ }$ & $\sqrt{ }$ & $\sqrt{ }$ & $\sqrt{ }$ & $\sqrt{ }$ & & $\sqrt{ }$ & $\sqrt{ }$ & $\sqrt{ }$ & $\sqrt{ }$ & & $\sqrt{ }$ \\
\hline Bulgaristan & $\sqrt{ }$ & $\sqrt{ }$ & $\sqrt{ }$ & $\sqrt{ }$ & $\sqrt{ }$ & $\sqrt{ }$ & & & & $\sqrt{ }$ & $\sqrt{ }$ & & & $\sqrt{ }$ \\
\hline Kibris & $\sqrt{ }$ & $\sqrt{ }$ & $\sqrt{ }$ & $\sqrt{ }$ & $\sqrt{ }$ & & & & $\sqrt{ }$ & $\sqrt{ }$ & $\sqrt{ }$ & & & $\sqrt{ }$ \\
\hline Danimarka & $\sqrt{ }$ & $\sqrt{ }$ & $\sqrt{ }$ & $\sqrt{ }$ & $\sqrt{ }$ & $\sqrt{ }$ & $\sqrt{ }$ & & $\sqrt{ }$ & $\sqrt{ }$ & $\sqrt{ }$ & $\sqrt{ }$ & $\sqrt{ }$ & $\sqrt{ }$ \\
\hline Estonya & $\sqrt{ }$ & $\sqrt{ }$ & $\sqrt{ }$ & $\sqrt{ }$ & $\sqrt{ }$ & $\sqrt{ }$ & $\sqrt{ }$ & & . & $\sqrt{ }$ & $\sqrt{ }$ & $\sqrt{ }$ & & $\sqrt{ }$ \\
\hline Finlandiya & $\sqrt{ }$ & $\sqrt{ }$ & $\sqrt{ }$ & $\sqrt{ }$ & $\sqrt{ }$ & $\sqrt{ }$ & $\sqrt{ }$ & & $\sqrt{ }$ & $\sqrt{ }$ & $\sqrt{ }$ & $\sqrt{ }$ & & $\sqrt{ }$ \\
\hline Fransa & $\sqrt{ }$ & $\sqrt{ }$ & $\sqrt{ }$ & $\sqrt{ }$ & $\sqrt{ }$ & $\sqrt{ }$ & $\sqrt{ }$ & & $\sqrt{ }$ & $\sqrt{ }$ & $\sqrt{ }$ & $\sqrt{ }$ & & $\sqrt{ }$ \\
\hline Almanya & $\sqrt{ }$ & $\sqrt{ }$ & $\sqrt{ }$ & $\sqrt{ }$ & $\sqrt{ }$ & $\sqrt{ }$ & $\sqrt{ }$ & & $\sqrt{ }$ & $\sqrt{ }$ & $\sqrt{ }$ & $\sqrt{ }$ & & $\sqrt{ }$ \\
\hline Yunanistan & $\sqrt{ }$ & $\sqrt{ }$ & $\sqrt{ }$ & $\sqrt{ }$ & $\sqrt{ }$ & $\sqrt{ }$ & $\sqrt{ }$ & & $\sqrt{ }$ & $\sqrt{ }$ & $\sqrt{ }$ & $\sqrt{ }$ & & $\sqrt{ }$ \\
\hline İzlanda & $\sqrt{ }$ & $\sqrt{ }$ & & $\sqrt{ }$ & $\sqrt{ }$ & $\sqrt{ }$ & & & $\sqrt{ }$ & $\sqrt{ }$ & $\sqrt{ }$ & & & \\
\hline İrlanda & $\sqrt{ }$ & $\sqrt{ }$ & $\sqrt{ }$ & $\sqrt{ }$ & $\sqrt{ }$ & $\sqrt{ }$ & & & & $\sqrt{ }$ & $\sqrt{ }$ & $\sqrt{ }$ & & $\sqrt{ }$ \\
\hline Letonya & $\sqrt{ }$ & $\sqrt{ }$ & $\sqrt{ }$ & $\sqrt{ }$ & $\sqrt{ }$ & $\sqrt{ }$ & & & . & $\sqrt{ }$ & $\sqrt{ }$ & $\sqrt{ }$ & & $\sqrt{ }$ \\
\hline Litvanya & $\sqrt{ }$ & $\sqrt{ }$ & $\sqrt{ }$ & $\sqrt{ }$ & $\sqrt{ }$ & $\sqrt{ }$ & & & . & $\sqrt{ }$ & $\sqrt{ }$ & $\sqrt{ }$ & & $\sqrt{ }$ \\
\hline Malta & $\sqrt{ }$ & $\sqrt{ }$ & $\sqrt{ }$ & $\sqrt{ }$ & $\sqrt{ }$ & $\sqrt{ }$ & $\sqrt{ }$ & & . & $\sqrt{ }$ & $\sqrt{ }$ & & & $\sqrt{ }$ \\
\hline Hollanda & $\sqrt{ }$ & $\sqrt{ }$ & $\sqrt{ }$ & $\sqrt{ }$ & $\sqrt{ }$ & $\sqrt{ }$ & $\sqrt{ }$ & & $\sqrt{ }$ & $\sqrt{ }$ & $\sqrt{ }$ & $\sqrt{ }$ & & $\sqrt{ }$ \\
\hline Norveç & $\sqrt{ }$ & $\sqrt{ }$ & $\sqrt{ }$ & $\sqrt{ }$ & $\sqrt{ }$ & $\sqrt{ }$ & $\sqrt{ }$ & & $\sqrt{ }$ & $\sqrt{ }$ & $\sqrt{ }$ & $\sqrt{ }$ & $\sqrt{ }$ & $\sqrt{ }$ \\
\hline Polonya & $\sqrt{ }$ & $\sqrt{ }$ & $\sqrt{ }$ & $\sqrt{ }$ & $\sqrt{ }$ & $\sqrt{ }$ & $\sqrt{ }$ & & $\sqrt{ }$ & $\sqrt{ }$ & $\sqrt{ }$ & $\sqrt{ }$ & & $\sqrt{ }$ \\
\hline Portekiz & $\sqrt{ }$ & $\sqrt{ }$ & $\sqrt{ }$ & $\sqrt{ }$ & $\sqrt{ }$ & $\sqrt{ }$ & $\sqrt{ }$ & & $\sqrt{ }$ & $\sqrt{ }$ & $\sqrt{ }$ & $\sqrt{ }$ & & $\sqrt{ }$ \\
\hline Romanya & $\sqrt{ }$ & $\sqrt{ }$ & $\sqrt{ }$ & $\sqrt{ }$ & $\sqrt{ }$ & $\sqrt{ }$ & & & & $\sqrt{ }$ & & & & $\sqrt{ }$ \\
\hline Slovenya & $\sqrt{ }$ & $\sqrt{ }$ & $\sqrt{ }$ & $\sqrt{ }$ & $\sqrt{ }$ & $\sqrt{ }$ & $\sqrt{ }$ & & & $\sqrt{ }$ & $\sqrt{ }$ & $\sqrt{ }$ & & $\sqrt{ }$ \\
\hline İspanya & $\sqrt{ }$ & $\sqrt{ }$ & $\sqrt{ }$ & $\sqrt{ }$ & $\sqrt{ }$ & $\sqrt{ }$ & $\sqrt{ }$ & & $\sqrt{ }$ & $\sqrt{ }$ & $\sqrt{ }$ & $\sqrt{ }$ & & $\sqrt{ }$ \\
\hline İsveç & $\sqrt{ }$ & $\sqrt{ }$ & $\sqrt{ }$ & $\sqrt{ }$ & $\sqrt{ }$ & $\sqrt{ }$ & $\sqrt{ }$ & & $\sqrt{ }$ & $\sqrt{ }$ & $\sqrt{ }$ & $\sqrt{ }$ & & $\sqrt{ }$ \\
\hline Türkiye & $\sqrt{ }$ & $\sqrt{ }$ & $\sqrt{ }$ & $\sqrt{ }$ & $\sqrt{ }$ & $\sqrt{ }$ & $\sqrt{ }$ & & & $\sqrt{ }$ & $\sqrt{ }$ & $\sqrt{ }$ & $\sqrt{ }$ & $\sqrt{ }$ \\
\hline Birleşik Krallık & $\sqrt{ }$ & $\sqrt{ }$ & $\sqrt{ }$ & $\sqrt{ }$ & $\sqrt{ }$ & $\sqrt{ }$ & & & & $\sqrt{ }$ & $\sqrt{ }$ & $\sqrt{ }$ & & $\sqrt{ }$ \\
\hline
\end{tabular}




\section{Kaynaklar}

Cunha, I., Moreira, S. ve Santos, M.M., (2015), Review on hazardous and noxious substances (HNS) involved in marine spill incidents-An online database, Journal of Hazardous Materials, 285, 509-516.

Çiçek, K. (2018), International Convention On Oil Pollution Preparedness, Response And CoOperation (Oprc) 1990 And Its Applications Related With Oil Spill In Turkey. Oil Spill Along The Turkish Straits Sea Area; Accidents, Environmental Pollution, Socio-Economic Impacts And Protection. Ed. Ünlü, S., Alpar. B. veÖztürk, B. Turkish Marine Research Foundation: İstanbul.

Danish Maritime Authority (2009) Implementation of the OPRC-HNS Protocol Pollution Incident Emergency Plan (PIEP), https://www.dma.dk/SynRegistrering/Syn/Cirkul aerer/Cirklulaerer3/DMA\%20010\%20ver\%2001 $\% 20$

$\%$ 20Implementation $\% 20$ of $\% 20$ the $\% 20$ OPRC-

HNS\%20Protocol.pdf\#search=piep, Accessed 22 February2019.

EMSA (European Maritime Safety Agency), (2013), Inventory of EU Member States' Policies and Operational Response Capacities for Hazardous and Noxious Substances Marine Pollution, Lisbon.

Hänninen, S., \& Rytkönen, J. (2006). Transportation of liquid bulk chemicals by tankers in the Baltic Sea. VTT.

IMO (International Maritime Organization), (2019), Protocol on Preparedness, Response and Cooperation to pollution Incidents by Hazardous and Noxious Substances, 2000 (OPRC-HNS Protocol),

http://www.imo.org/en/About/Conventions/ListO f Conventions/Pages/Protocol-on-Preparedness,Response-and-Co-operation-to-pollutionIncidents-by-Hazardous-and-NoxiousSubstances-(OPRC-HNS-Pr.aspx; Access Date: 09.08.2019.

ITOPF (International Tanker Owners Pollution Federation), https://www.itopf.org/knowledgeresources/countries-territoriesregions/countries/estonia/, Accessed 21.01.2019.

ITOPF (International Tanker Owners Pollution Federation), (2018b), https://www.itopf.org/knowledgeresources/countries-territoriesregions/countries/finland/, Accessed 21.01.2019.
ITOPF (International Tanker Owners Pollution Federation), (2018c), https://www.itopf.org/knowledgeresources/countries-territoriesregions/countries/france/, Accessed 21.01.2019.

ITOPF (International Tanker Owners Pollution Federation), https://www.itopf.org/knowledge(2018d), resources/countries-territoriesregions/countries/germany/

Accessed 23.01.2019.

ITOPF (International Tanker Owners Pollution Federation), (2018e), https://www.itopf.org/knowledgeresources/countries-territoriesregions/countries/iceland/, Accessed 23.01.2019.

ITOPF (International Tanker Owners Pollution Federation), (2018f), https://www.itopf.org/knowledgeresources/countries-territoriesregions/countries/latvia/, Accessed 23.01.2019.

ITOPF (International Tanker Owners Pollution Federation), https://www.itopf.org/knowledgeresources/countries-territoriesregions/countries/poland/, Accessed 27.01.2019.

ITOPF (International Tanker Owners Pollution Federation), (2018h), https://www.itopf.org/knowledgeresources/countries-territoriesregions/countries/romania/, 28.01.2019.

Accessed

ITOPF (International Tanker Owners Pollution Federation), https://www.itopf.org/knowledgeresources/countries-territoriesregions/countries/slovenia/, 30.01.2019.

ITOPF (International Tanker Owners Pollution Federation), (2018j), https://www.itopf.org/knowledgeresources/countries-territoriesregions/countries/sweden/, Accessed 30.01.2019.

ITOPF (International Tanker Owners Pollution Federation), https://www.itopf.org/knowledgeresources/countries-territoriesregions/countries/sweden/, Accessed 30.01.2019.

ITOPF (International Tanker Owners Pollution Federation), (2018m), https://www.itopf.org/knowledgeresources/countries-territoriesregions/countries/united-kingdom/, Accessed 21.01.2019 
KEGM (2019), Kıyı Emniyeti Genel Müdürlüğü, Konuşlandırılması Düşünülenn Acl Durum İstasyonlar1, https://www.kiyiemniyeti.gov.tr/acil_mudahale, Erişim Tarihi: 20.02.2020.

Neuparth T., Moreira, S., Santos, M.M. \& ReisHenriques, M.A. (2011) Hazardous and Noxious Substances (HNS) in the marine environment: Prioritizing HNS that pose major risk in a European context. Marine Pollution Bulletin, 62(1),21-28.

Neuparth, T., Capela, R., Rey-Salgueiro, L., Moreira, S., Santos, M.M\& Reis-Henriques M.A. (2013) Simulation of a Hazardous and Noxious Substances (HNS) spill in the marine environment: Lethal and sublethal effects of acrylonitrile to the European seabass, Chemosphere, 93(6), 978-985.

OECD (Organisation for Economic Co-operation and Development), (2007a), Environmental Performance Reviews - Belguim, USA: OECD

OECD (Organisation for Economic Co-operation and Development), (2007b), Environmental Performance Reviews - Denmark, USA: OECD

OECD (Organisation for Economic Co-operation and Development), (2009), Environmental Performance Reviews - Greece, USA: OECD

OECD (Organisation for Economic Co-operation and Development), (2010), Environmental Performance Reviews - Ireland, USA: OECD

OECD (Organisation for Economic Co-operation and Development), (2011), Environmental Performance Reviews - Portugal, USA: OECD

Oral, N. (2013). Regional co-operation and protection of the marine environment under international law: the Black Sea. Martinus Nijhoff Publishers.

Sormunen, O. V. E., Goerlandt, F., Häkkinen, J., Posti, A., Hänninen, M., Montewka, J., ... \& Kujala, P. (2015). Uncertainty in maritime risk analysis: Extended case study on chemical tanker collisions. Proceedings of the Institution of Mechanical Engineers, Part M: Journal of Engineering for the Maritime Environment, 229(3), 303-320. 